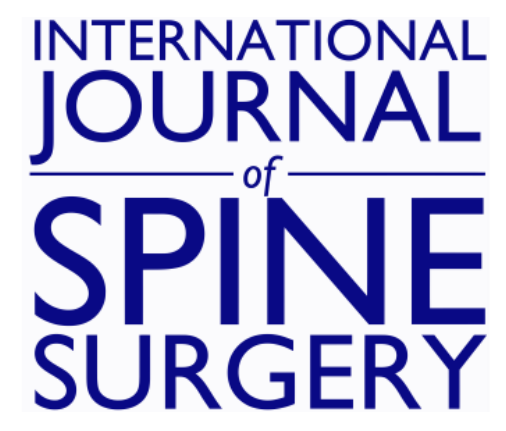

\title{
Long-term Evaluation of Cervical Disc Arthroplasty with the Mobi-C(C) Cervical Disc: A Randomized, Prospective, Multicenter Clinical Trial with Seven-Year Follow-up
}

Kris Radcliff, Reginald J. Davis, Michael S. Hisey, Pierce D. Nunley, Gregory A. Hoffman, Robert J. Jackson, Hyun W. Bae, Todd Albert and Dom Coric

Int J Spine Surg 2017, 11 (4)

doi: https://doi.org/10.14444/4031

http://ijssurgery.com/content/11/4/31

This information is current as of April 26, 2023.

Email Alerts Receive free email-alerts when new articles cite this article. Sign up at:

http://ijssurgery.com/alerts

The International Journal of Sping Surgerbhttp://ijssurgery.com/ by guest on April 26, 2 2397 Waterbury Circle, Suite 1, 


\section{Long-term Evaluation of Cervical Disc Arthroplasty with the Mobi-C@ Cervical Disc: A Randomized, Prospective, Multicenter Clinical Trial with Seven-Year Follow-up}

Kris Radcliff, MD,1 Reginald J. Davis, MD,2 Michael S. Hisey, MD, ${ }^{3}$ Pierce D. Nunley, MD, 4 Gregory A. Hoffman, MD,5 Robert J. Jackson, MD, 6 Hyun W. Bae, $M D, 7$ Todd Albert, $M D,{ }^{8}$ Dom Coric, $M D^{9}$

${ }_{1}$ Department of Orthopedic Surgery, Rothman Institute, Thomas Jefferson University, Egg Harbor, NJ, 2Greater Baltimore Neurosurgical Associates, Baltimore, MD, ${ }^{3}$ Texas Back Institute, Plano, TX, ${ }^{4}$ Spine Institute of Louisiana, Shreveport, LA, 5 Orthopedics Northeast, Fort Wayne, IN, 6 Orange County Neurosurgical Associates, Laguna Hills, CA, ${ }^{7}$ Cedars-Sinai Spine Center, Los Angeles, CA, ${ }^{8}$ Hospital for Special Surgery, Cornell Medical College, New York, $N Y,{ }^{9}$ Carolinas Medical Center, Carolina Neurosurgery \& Spine Associates, Charlotte, NC

\section{Abstract}

\section{Background}

Cervical total disc replacement (TDR) is an increasingly accepted procedure for the treatment of symptomatic cervical degenerative disc disease. Multiple Level I evidence clinical trials have established cervical TDR to be a safe and effective procedure in the short-term. The objective of this study is to provide a long-term assessment of TDR versus anterior discectomy and fusion for the treatment of one- and two-level disc disease.

\section{Methods}

This study was a continuation of a prospective, multicenter, randomized, US FDA IDE clinical trial comparing cervical TDR with the Mobi-C ${ }^{\odot}$ Cervical Disc versus ACDF through 7 years follow-up. Inclusion criteria included a diagnosis of symptomatic cervical degenerative disc disease at one or two cervical levels. TDR patients were treated using a Mobi-C ${ }^{\odot}$ artificial disc (Zimmer Biomet, Austin TX, USA). ACDF with allograft and anterior plate was used as a control treatment. Outcome measures were collected preoperatively and postoperatively at 6 weeks, at 3,6,12, 18 months, annually through 60 months, and at 84 months. Measured outcomes included Overall success, Neck Disability Index (NDI), VAS neck and arm pain, segmental range of motion (ROM), patient satisfaction, SF-12 MCS/PCS, major complications, and subsequent surgery rate. The primary endpoint was an FDA composite definition of success comprising clinical improvement and an absence of major complications and secondary surgery events.

Results

A total of 599 patients were enrolled and treated, with 164 treated with one-level TDR, 225 treated with two-level TDR, 81 treated with one-level ACDF, and 105 treated with two-level ACDF. At seven years, follow-up rates ranged from $73.5 \%$ to $84.4 \%$ (overall $80.2 \%$ ).

The overall success rates of two level TDR and ACDF patients were $60.8 \%$ and $34.2 \%$, respectively $(\mathrm{p}<0.0001)$. The overall success rates of one level TDR and ACDF patients were $55.2 \%$ and $50 \%$, respectively ( $>>0.05)$. Both the single and two level TDR and ACDF groups showed significant improvement from baseline NDI scores, VAS neck and arm pain scores, and SF-12 MCS/PCS scores $(\mathrm{p}<0.0001)$. In the single level cohort, there was an increased percentage of TDR patients who reported themselves as "very satisfied" (TDR 90.9\% vs ACDF 77.8\%; $\mathrm{p}=$ 0.028). There was a lower rate of adjacent level secondary surgery in the single level TDR patients (3.7\%) versus the ACDF patients $(13.6 \% ; \mathrm{p}=0.007)$.

In the two level TDR group, the NDI success rate was significantly greater in the TDR group (TDR: $79.0 \%$ vs. ACDF: 58.0\%; $\mathrm{p}=0.001)$. There was significantly more improvement in NDI change score at 7 years in the TDR patients versus ACDF. The TDR group had a significantly higher rate of patients who were "very satisfied" with their treatment compared to the ACDF group (TDR: $85.9 \%$ vs. ACDF: 73.9\%). The rate of subsequent surgery at the index level was significantly lower in the TDR group compared to the ACDF group (TDR: 4.4\% vs. ACDF: 
$16.2 \% ; \mathrm{p}=0.001)$. The rate of adjacent level secondary surgery was significantly lower in the two level TDR (4.4\%) patients compared to the ACDF $(11.3 \% ; \mathrm{p}=0.03)$ patients. In both single and two level cohorts, the percentage of patients with worse NDI (2.5\%-3.8\% of two level surgeries and 1.2\%-2.5\% of single level surgeries) or worse neck pain (5\%-6.8\% of the two level surgeries and $1.3 \%-3.8 \%$ of the single level surgeries) was strikingly low in both groups but trended lower in the TDR patients.

\section{Conclusions}

At seven years, the composite success analysis demonstrated clinical superiority of two level TDR over ACDF and non-inferiority of single level TDR versus ACDF. There were lower rates of secondary surgery and higher adjacent level disc survivorship in both groups. Both surgeries were remarkably effective in alleviating pain relative to baseline and the rate of patients with worse disability or neck pain was surprisingly low. Overall, greater than $95 \%$ of patients (from both groups) who underwent TDR and 88\% of patients who underwent ACDF were "very satisfied" at seven years. The differences in clinical effectiveness of TDR versus ACDF becomes more apparent as treatment increases from one to two levels, indicating a significant benefit for TDR over ACDF for two-level procedures.

\section{Ethical Standards}

The Mobi-C Clinical Trial (ClinicalTrials.gov registration number: NCT00389597) was conducted at 24 sites in the US and was approved by the Institutional Review Board, Research Ethics Committee, or local equivalent of each participating site.

\section{Level of Evidence}

1.

$T D R$

KEYWORDS: CERVICAL TOTAL DISC REPLACEMENT, ACDF, DEGENERATIVE DISC DISEASE, MOBI-C

VOLUME 11 ISSUE 4 DOI: $10.14444 / 4031$

PAGES $244-262$

\section{Introduction}

Neck and arm pain have shown to negatively impact multiple facets of patient health ${ }^{1}$ and neck pain alone remains one of the largest contributors to the overall global heath burden. ${ }^{2}$ Since the mid-20th Century, the standard surgical procedure for treating symptomatic cervical spondylosis has been anterior discectomy and fusion (ACDF). While ACDF is a highly effective procedure, there are two major, procedurespecific complications: pseudoarthrosis and adjacent segment degeneration (ASD). ${ }^{3}$

The causative relationship between ACDF and ASD most likely lies in the kinematics and functionality of the partially fused spine. As motion in treated segments is eliminated through fusion, adjacent segments become hypermobile and adjacent discs experience increased loads and stresses..$^{47}$ In turn, these kinematic changes have the potential to initiate or accelerate pathologies in intact segments. Unfortunately, the immobility of treated segments is the very nature of the fusion procedure, required for stabiliza- tion after discectomy. As such, it seems only natural to seek an alternative surgical technique in which natural, healthy motion is preserved or restored.

Cervical total disc replacement (TDR) was developed in an effort to preserve natural spinal kinematics while providing mechanical stabilization after neural decompression and discectomy. Several Level I evidence randomized clinical trials have confirmed both the safety and efficacy of TDR in both the short- and long-term. ${ }^{8-14}$ TDR has shown to have many possible advantages over ACDF including lower rates of subsequent surgical intervention, ${ }^{15,16}$ lower rates of adjacent segment degeneration, ${ }^{13,17,18}$ and an advantage in cost-effectiveness. ${ }^{19,20}$ Furthermore, kinematic analyses have shown TDR to maintain functional biomechanics at the level treated while mitigating excess motion at adjacent segments. ${ }^{21}$

The purpose of this study is to expand on results from the Mobi- ${ }^{\odot}$ Cervical Disc FDA IDE clinical trial with 7-year data. Previously reported $2{ }^{13,22}$, $4{ }^{14,23}$, and 5-year ${ }^{24,25}$ follow-up results from this ran- 
domized clinical trial have shown equivalent or better performance of TDR compared to ACDF at both one and two levels of treatment. Here, we present 7-year results from the one and two level arms for a comprehensive, long-term evaluation of TDR with Mobi-C ${ }^{\odot}$.

\section{Methods}

\section{Study Design and Patient Population}

The study was a prospective, randomized multicenter clinical trial conducted at 24 sites in the US. The study was divided into two separate arms of one-level and two-level treatment, conducted in tandem. Enrollment criteria included a diagnosis of degenerative disc disease with radiculopathy or myeloradiculopathy at either one or two contiguous levels from $\mathrm{C} 3$ to C7. General inclusion and exclusion criteria are listed in Table 1.

Patients were randomized in a 2:1 ratio (investigational: control) and received surgery between April 2006 and March 2008. The investigational group was treated with TDR using the Mobi-C ${ }^{\odot}$ Cervical Disc (Mobi-C, Zimmer Biomet, Austin, TX, USA) (Figure 1). The control group received ACDF with allograft and anterior plate. A total of 164 patients were treated with one-level TDR, 81 with one-level ACDF, 225 with two-level TDR, and 105 with twolevel ACDF. Surgeons were blinded up to the time of the procedure and patients were blinded until after surgery. Blinding afterwards was not possible due to differences in postoperative recovery protocols and the ability for patients to view their own radiographs.

Postoperative recovery schemes were left to the discretion of the treating surgeons. All patients were instructed to refrain from taking non-steroidal antiinflammatory drugs (NSAIDs) a week before surgery until 3 months post-surgery. Patients were followed at 6 weeks, 3 months, 6 months, annually to 5 years, and then again at 7 years. A detailed description of the study design, including surgical technique, has been previously published by Davis et al (2013). ${ }^{13} \mathrm{~A}$ CONSORT diagram is included in the Appendix.

\section{Outcome Measures}

Patient reported clinical outcomes included the neck disability index (NDI), the visual analog scale (VAS) for neck and arm pain, the short-form 12-item questionnaire (SF-12) for physical health (PCS) and mental health (MCS), and a patient satisfaction survey. For VAS arm pain, the mean improvement from baseline is reported for the most symptomatic arm at preoperative. In the event that a patient had equal preoperative VAS arm pains scores, the improvement in both arms was taken as the average improvement of both arms. To account for differences at presentation between patients and facilitate explanation

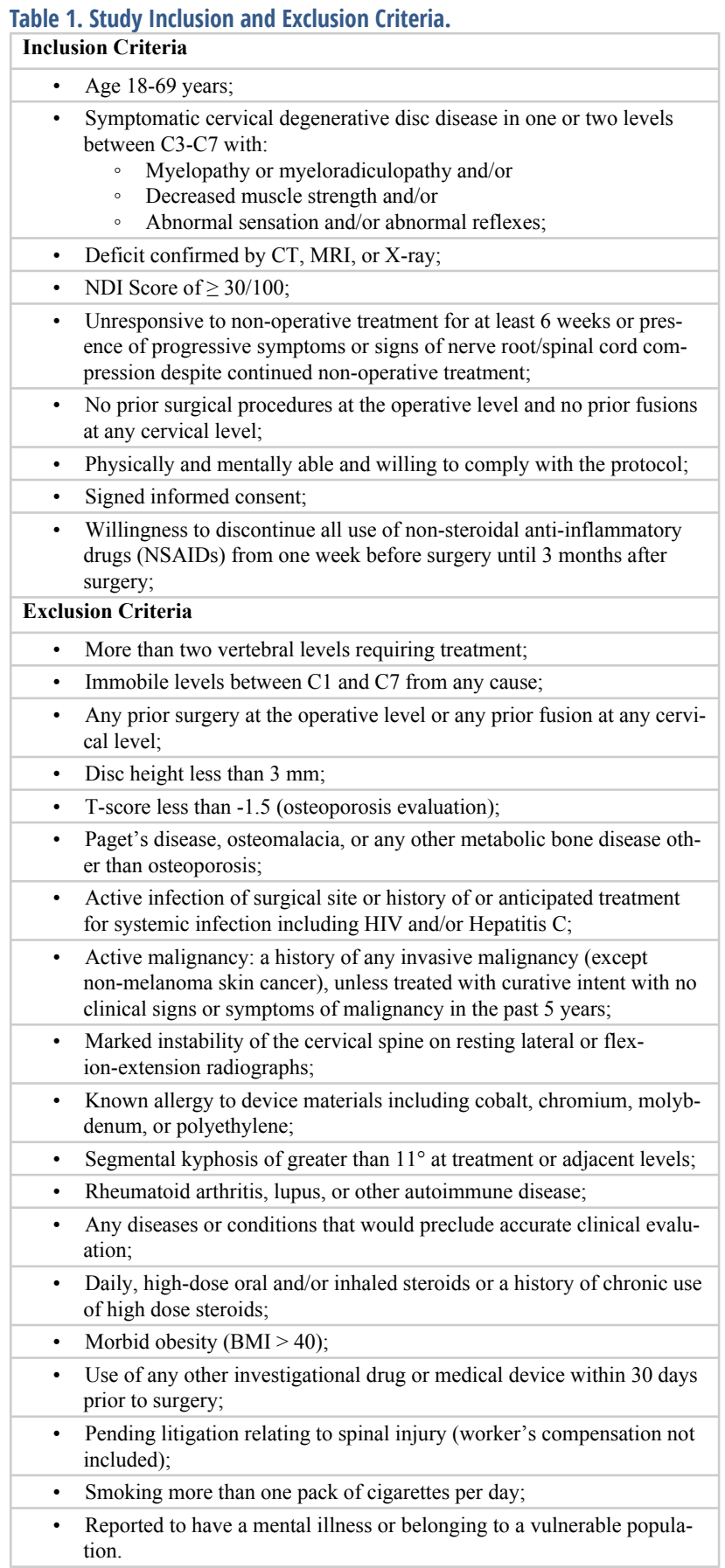


of the data to non-spine providers, recovery ratios (RR) were calculated as the percentage difference between pre- and post-operative scores using the method of Hirabayashi: ${ }^{26}$

\section{$\mathbf{R R}=([$ Follow-up score $]-$ [Baseline score $]) /$ ([Optimum score] - [Baseline score])}

where optimum score is the best possible score for that outcome measure (e.g. 0 for VAS, 100 for SF-12). The recovery ratio represents the improvement in outcome normalized to the patient's baseline outcome score relative to the possible improvement in outcome.

Patients were asked two questions related to satisfaction. For patient satisfaction, patients were surveyed if they were "very satisfied," "somewhat satisfied," "somewhat dissatisfied," or "very dissatisfied" with their treatment. Patients were also asked how likely they were to recommend their respective surgery to a friend with possible responses of "definitely," "probably," "probably not," and "definitely not." For the purposes of this investigation, high likelihood to recommend was calculated as the proportion of patients who answered "definitely yes" or "probably yes" for the questionnaire.

Radiographic outcomes included measurements of flexion-extension and lateral bending range of motion (ROM), functional spinal unit height, heterotopic ossification, and adjacent segment degeneration. Heterotopic ossification was assessed using the grading system adapted from McAfee and Mehren. ${ }^{27,28}$ Adja-

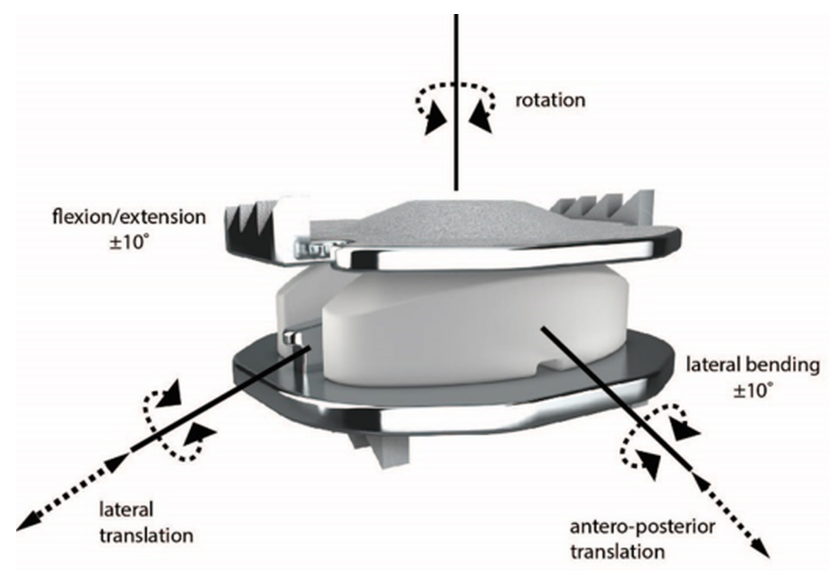

Fig. 1. The Mobi-C@ Cervical Disc. cent segment degeneration was assessed using the grading system adapted from Kellgren and Lawrence. ${ }^{29}$ A team of independent radiologists (Medical Metrics, Inc., Houston, TX) made all radiographic determinations.

\section{Primary Success Endpoint}

The primary endpoint for the study was a composite definition of patient success. In order to be considered a success, a patient had to meet each of the following criteria:

- An improvement in NDI score of at least 30 points for a patient with a preoperative NDI score of 60 or greater; or an improvement of at least $50 \%$ of preoperative NDI score for patients with a preoperative score of less than 60 ;

- No subsequent surgical intervention at the index level(s);

- No adverse events (AEs) classified as major complications by a clinical events committee (CEC);

- Maintenance or improvement in neurologic function;

- Radiographic success.

All subsequent surgeries were collected and documented in detail consistent with previous descriptions. ${ }^{13,15,24,25}$ The study protocol did not specify the indications for reoperation in either treatment group. The decision for subsequent surgical intervention was determined solely by the treating surgeon and the patient's personal decision to proceed. Consistent with other analyses, ${ }^{9,11,15,18}$ index-level secondary surgeries were categorized when possible as a revision, removal, reoperation or supplemental fixation. Essentially, any surgery that touched the index level was considered as an index-level reoperation, even if the primary goal of surgery was to correct an adjacent level problem. Secondary operations at adjacent levels were documented as well. Thus, operations at adjacent levels only were not considered in the primary success-or-failure study endpoint. However, operations that involved both index and adjacent levels were considered in the primary success or failure study endpoint. For plate removals, if the plate was removed from the index level to extend the fusion to an adjacent level, this event was considered a removal per the study protocol and considered a failure 
for the primary endpoint.

Adverse events (AEs) were defined as any clinically adverse sign, symptom, syndrome, or illness that occurred or worsened during the operative and postoperative period. AEs were assessed by a Clinical Events Committee (CEC) composed of two orthopedic surgeons and one neurosurgeon. The members of the CEC were not investigators on the study and were blinded to treatment whenever possible. Any patient with an $\mathrm{AE}$ that was determined by the CEC to be a major complication of the treatment was considered a study failure.

Neurological assessments were performed by the investigator using tests of sensory, reflex, and motor function. Any patient with a decrease in sensory, reflex, or motor function from preoperative status was considered a failure.

For the TDR group, radiographic success was defined as at least $2^{\circ}$ of segmental motion in flexionextension or no evidence of bridging bone across the disc space. Grade IV heterotopic ossification was an indication of bridging bone. For the ACDF group, radiographic success was defined as fusion of the treated level(s), less than $2^{\circ}$ of segmental motion in flexion-extension, and evidence of bridging bone across the disc space with radiolucent lines at no more than $50 \%$ of the graft vertebral interfaces.

\section{Statistical Methods}

The primary endpoint was assessed with the hypothesis of non-inferiority of TDR versus ACDF with a $10 \%$ non-inferiority margin. Non-inferiority was tested using a 95\% one-sided lower confidence bound of the difference between the investigation and the control group. A closed testing procedure was prespecified for superiority, to be tested in the event that noninferiority was confirmed. If non-inferiority was confirmed, superiority was tested using a 95\% lower confidence bound.

There were two distinct methods of outcome assessment. To evaluate the change in outcomes specifically at seven years, $p$-values for differences in improvement from baseline in NDI, VAS, and SF-12 scores at 84 months were calculated using repeated measures, mixed effects ANOVA adjusted for multiplicity.

A global outcome assessment was also performed to evaluate the aggregate change in outcome over the entire seven year study period (inclusive of all of the previous time points including two year, five year, and seven year time points). Global p-values for differences in absolute NDI, VAS, and SF-12 scores between TDR and ACDF were calculated using repeated measures, mixed effects ANOVA across all postoperative time points.

Secondary surgery survival function estimates were generated using the Kaplan-Meier method, with the log-rank test to compare survival functions. Patients undergoing a removal, revision, or supplemental fixation procedure were censored at all time points after the surgery for secondary outcomes (e.g. NDI, VAS). P-values for categorical endpoints were calculated using a two-sided Fisher's exact test. Statistical analyses were performed using SAS version 9.4 (SAS Institute, Cary, NC). All patients that were discontinued (e.g. withdrawn, lost-to-follow-up, device removal) were censored at their last follow-up prior to study withdrawal. A scenario analysis was performed to determine the potential influence of discontinued patients, including last observation carried forward (best-case scenario), and all discontinued patients counted as failures (worst-case scenario analysis). Under each scenario analysis, TDR remained either superior or non-inferior to ACDF.

\section{Results}

Preoperative patient characteristics and clinical outcomes were similar between treatment groups within treatment arms (Table 2). The inclusion criteria required that patients smoke less than one pack per day, but the preoperative smoking status of each patient was not collected as part of the study protocol. However, a post-hoc survey conducted by the investigators estimated the proportion of smokers in the study to be $15.1 \%$ for ACDF patients and $18.7 \%$ for TDR patients. ${ }^{30}$ At 7 years, the follow-up rate was $84.4 \%$ for the two-level TDR group, and $75.0 \%$ for the two-level ACDF group, and $80.1 \%$ for the one-level TDR group and 74.3\% for the one-level ACDF group. The follow-up rates were calculated using the FDA 
guidelines for orthopedic device clinical trials. ${ }^{31}$

\section{Two-Level Treatment Arm}

Primary Success Analysis - Two level

At 7 years, two-level TDR demonstrated superiority compared to two-level ACDF (Figure 2). The rate of success was $60.8 \%(104 / 171)$ in the TDR group and $34.6 \%(27 / 78)$ in the ACDF group with a difference of $26.2 \%$ and lower $95 \%$ confidence bound of $15.4 \%$. Analyzing the individual components of success illustrates that the primary driver of 2-level TDR superiority was due to a significant difference in percentage of successful NDI scores (TDR 79\% vs ACDF 58\%), lower incidence of subsequent surgery (4.4\% vs $16.2 \%)$, and lower incidence of neurological failure (6.4\% vs $17.1 \%$; Table 3$)$. The differential success of TDR was not attributable to differences in the rate of adverse events or radiological deterioration between groups.

Patient Reported Outcomes - Two level

Two-level TDR and ACDF patients had similar preoperative NDI scores, and NDI at all follow-ups was significantly improved from baseline for both treat- ments though seven years. Globally, TDR patients had significantly lower NDI scores than ACDF patients $(\mathrm{p}<0.0001$; Figure 3$)$ averaged across all followup periods. Specifically at the seven year followup endpoint, the TDR group also had greater improvement in NDI scores $(35.6 \pm 20)$ than the ACDF group $(28.2 \pm 21.7 ; \mathrm{p}=0.04)$ at 7 years (Table 4$)$. Considering the recovery ratios, NDI scores improved $67 \%$ over baseline in the TDR group and 53\% in the ACDF patients. For two-level patients, the most improved NDI item was Pain Intensity for ACDF (2.0 points) and Recreation for TDR (2.4 points). For

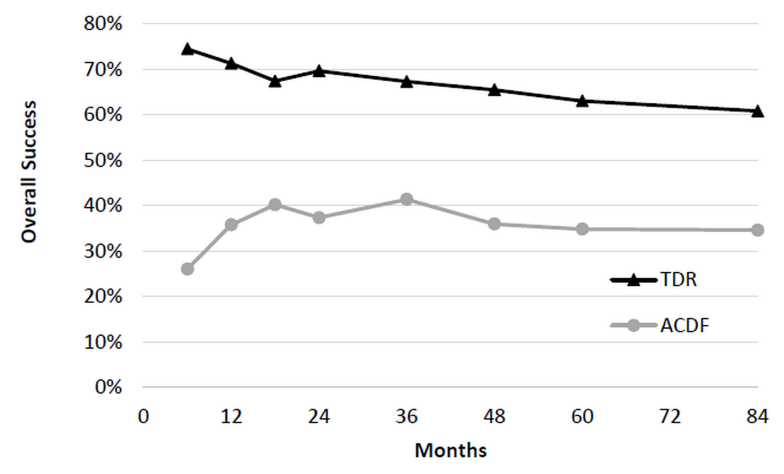

Fig. 2. Overall treatment success of two-level TDR and ACDF.

Table 2. Preoperative Patient Characteristics for TDR and ACDF.

\begin{tabular}{|c|c|c|c|c|}
\hline & \multicolumn{2}{|r|}{ 2-Level } & \multicolumn{2}{|r|}{ 1-Level } \\
\hline Characteristic & TDR & $\mathrm{ACDF}$ & TDR & $\mathrm{ACDF}$ \\
\hline $\mathrm{N}$ & 225 & 105 & 164 & 81 \\
\hline Age (years) (range) & $\begin{array}{r}45.3 \pm 8.1 \\
(21-67)\end{array}$ & $\begin{array}{r}46.2 \pm 8.0 \\
(27-65)\end{array}$ & $\begin{array}{r}43.3 \pm 9.2 \\
(23-67)\end{array}$ & $\begin{array}{r}44.0 \pm 8.2 \\
(27-66)\end{array}$ \\
\hline \multicolumn{5}{|l|}{ Gender n (\%) } \\
\hline Male & $113(50.2 \%)$ & $45(42.9 \%)$ & $78(47.6 \%)$ & $36(44.4 \%)$ \\
\hline Female & $112(49.8 \%)$ & $60(57.1 \%)$ & $86(52.4 \%)$ & $45(55.6 \%)$ \\
\hline BMI (SD) & $27.6(4.5)$ & $28.1(4.2)$ & $27.3(4.4)$ & $27.4(4.2)$ \\
\hline \multicolumn{5}{|l|}{ Work Status n (\%) } \\
\hline Able to work & $141(62.7 \%)$ & $64(61.0 \%)$ & $108(65.9 \%)$ & $46(56.8 \%)$ \\
\hline Not able to work & $50(22.2 \%)$ & $22(21.0 \%)$ & $37(22.6 \%)$ & $22(27.2 \%)$ \\
\hline Does not work & $34(15.1 \%)$ & $19(18.1 \%)$ & $19(11.6 \%)$ & $13(16.0 \%)$ \\
\hline \multicolumn{5}{|c|}{ Worker's Compensation n (\%) } \\
\hline Receiving & $11(4.9 \%)$ & $7(6.7 \%)$ & $6(3.7 \%)$ & $5(6.2 \%)$ \\
\hline Not Receiving & $214(95.1 \%)$ & $98(93.3 \%)$ & $158(96.3 \%)$ & $76(93.8 \%)$ \\
\hline \multicolumn{5}{|l|}{ Treated Segment(s) } \\
\hline $\mathrm{C} 3-\mathrm{C} 5$ & $1(0.4 \%)$ & $2(1.9 \%)$ & & \\
\hline C4-C6 & $60(26.7 \%)$ & $23(21.9 \%)$ & & \\
\hline $\mathrm{C} 5-\mathrm{C} 7$ & $164(72.9 \%)$ & $80(76.2 \%)$ & & \\
\hline $\mathrm{C} 3-\mathrm{C} 4$ & & & $1(0.6 \%)$ & $4(4.9 \%)$ \\
\hline $\mathrm{C} 4-\mathrm{C} 5$ & & & $11(6.7 \%)$ & $2(2.5 \%)$ \\
\hline C5-C6 & & & $92(56.1 \%)$ & $46(26.8 \%)$ \\
\hline C6-C7 & & & $60(36.6 \%)$ & $29(35.8 \%)$ \\
\hline
\end{tabular}

Values given are mean \pm SD unless otherwise indicated. 
Table 5. NDI and pain status (\% of patients) at last follow-up in 2-level TDR and ACDF.

\begin{tabular}{|c|c|c|c|c|c|c|}
\hline \multirow[b]{2}{*}{ Status* } & \multicolumn{3}{|r|}{ NDI } & \multicolumn{3}{|c|}{ VAS Neck Pain } \\
\hline & TDR & $\mathrm{ACDF}$ & P valuet & TDR & $\mathrm{ACDF}$ & P value $\dagger$ \\
\hline Improved & $80.8 \%$ & $70.2 \%$ & 0.10 & $86.0 \%$ & $77.7 \%$ & 0.15 \\
\hline Not improved & $16.5 \%$ & $25.9 \%$ & & $9.0 \%$ & $15.5 \%$ & \\
\hline
\end{tabular}

* NDI: Improved: $\geq 15 / 100$ point increase from baseline. Not improved: < 15 point change ( \pm ) from baseline. Worse: $\leq-15 / 100$ point decrease from baseline. Neck pain: Improved: $\geq 10 / 100$ point increase from baseline. Not improved: $<10$ point change $( \pm)$ from baseline. Worse: $\leq-10 / 100$ point decrease from baseline. † Fisher's exact test.

VAS neck pain and arm pain scores, both groups improved significantly compared to baseline by six weeks and maintained the improvement averaged across all followup periods (Figure 3). TDR patients had significantly lower VAS neck pain scores than ACDF patients averaged across all followup periods $(p=0.0002$; Figure 3$)$. At the specific 7 year followup time-point, the TDR group showed a nonsignificant trend toward more improvement in VAS neck scores $(50.9 \pm 30.6)$ than the ACDF group $(44.1 \pm 39 ; \mathrm{p}=0.21$; Table 4). At the 7 year followup endpoint, VAS neck pain improved $72 \%$ over baseline in the TDR group and $57 \%$ over baseline in the ACDF group. There was no apparent difference between TDR and ACDF with respect to VAS arm pain at the 7-year follow-up endpoint (Table 4).

The vast majority of patients demonstrated improvement in NDI in the two level cohort (80\% TDR and 70.2\% ACDF; Table 5) and there was a strikingly low percentage of patients who had worse NDI scores (2.7\% TDR and 3.8\% ACDF; $\mathrm{p}=0.10$ ). Overall, the vast majority of patients demonstrated improvement in VAS neck pain in both the two level cohort ( $86 \%$

Table 3. Overall success and components of success for 2-level TDR and ACDF.

\begin{tabular}{|l|r|r|r|}
\hline & TDR & ACDF & Difference \\
\hline Composite success & $60.8 \%$ & $34.6 \%$ & $26.2 \% *$ \\
\hline NDI success & $79.0 \%$ & $58.0 \%$ & $21.0 \% \dagger$ \\
\hline Subsequent Surgery & $4.4 \%$ & $16.2 \%$ & $11.8 \% \dagger$ \\
\hline Neurologic failure & $6.4 \%$ & $17.1 \%$ & $10.7 \% \dagger$ \\
\hline Adverse events & $5.3 \%$ & $8.6 \%$ & $3.3 \%$ \\
\hline Radiographic failure & $10.1 \%$ & $9.1 \%$ & $1.0 \%$ \\
\hline
\end{tabular}

* Superiority of TDR vs. ACDF established with 95\% lower confidence bound of difference $>0 \%$. $\dagger p<0.05$; Fisher's exact test.
TDR and 77.7\% ACDF; $\mathrm{p}=0.15)$ and the single level cohort (87.5\% TDR and 83.8\% ACDF; $p=0.21$ ). Similarly, there was a strikingly low percentage of patients who had worse NDI scores in both the two level cohort (5\% TDR and 6.8\% ACDF) and the single level cohort (3.8\% TDR and 1.3\% ACDF; Table 5).

Both patient groups saw a significant improvement in SF-12 PCS/MCS scores from baseline. TDR had significantly higher postoperative SF-12 PCS scores averaged across all time points ( $\mathrm{p}=0.0003)$, but $\mathrm{SF}-12$ MCS scores were similar in both treatment groups (Figure 3). At the specific seven year time point, there were no statistically significant differences in SF12 PCS or MCS scores.
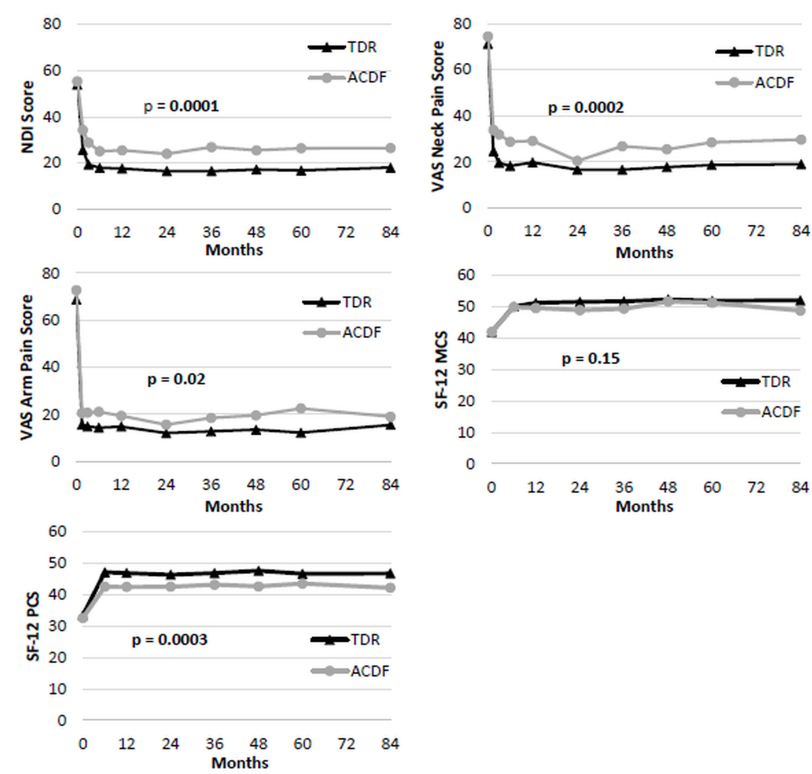

Fig. 3. Patient-reported outcomes for two-level TDR and ACDF Patients from preoperative to 7 years follow-up. P-values are from global test of the difference between TDR and ACDF patient scores, generalized across all time points. Top Left: Mean NDI scores. Top Right: Mean VAS Neck Pain scores. Middle Left: Mean VAS arm pain scores. Middle Right: Mean SF-12 MCS. Bottom Left: Mean SF-12 PCS. 
Overall patient satisfaction was high in both groups with high proportions of patients in both groups describing themselves as "very satisfied" [TDR: $86.0 \%$ $(160 / 186)$ vs. ACDF: 73.9\% (51/69); $\mathrm{p}=0.039]$. However, a higher proportion TDR patients answered they would "definitely" or "probably" recommend their treatment to a friend, when compared to the ACDF group [TDR: $96.8 \%(179 / 185)$ vs.

ACDF: $88.4 \%(61 / 69) ; \mathrm{p}=0.025]$.

Radiographic Outcomes - Two level

The TDR grouped maintained range of motion in flexion/extension and lateral bending at both treated levels (Figure 4). Both groups experienced a marginal decrease in functional spinal unit height relative to postoperative measurements at both the superior and inferior treated levels (Table 6). For 2-level TDR patients, bridging bone at either level was present in $11.1 \%$ of patients $(6.5 \%$ superior level/4.7\% inferior level). At 7 years, $90.9 \%$ of ACDF patients met the criteria for radiographic fusion. Both groups experienced adjacent segment degeneration. However, the ACDF group presented with double the prevalence of radiographic degeneration compared to the TDR group at both the inferior (TDR $30.3 \%$ vs ACDF 66.7\%) and superior (TDR 37.5\% vs ACDF $80.8 \%$ ) adjacent levels, respectively (Table 6).
Safety Outcomes - Two level

CEC classified adverse events rates were also similar between groups (TDR: 5.3\% (12/225), ACDF: 8.6\% (9/105)). TDR patients had significantly fewer subsequent surgical interventions than ACDF patients
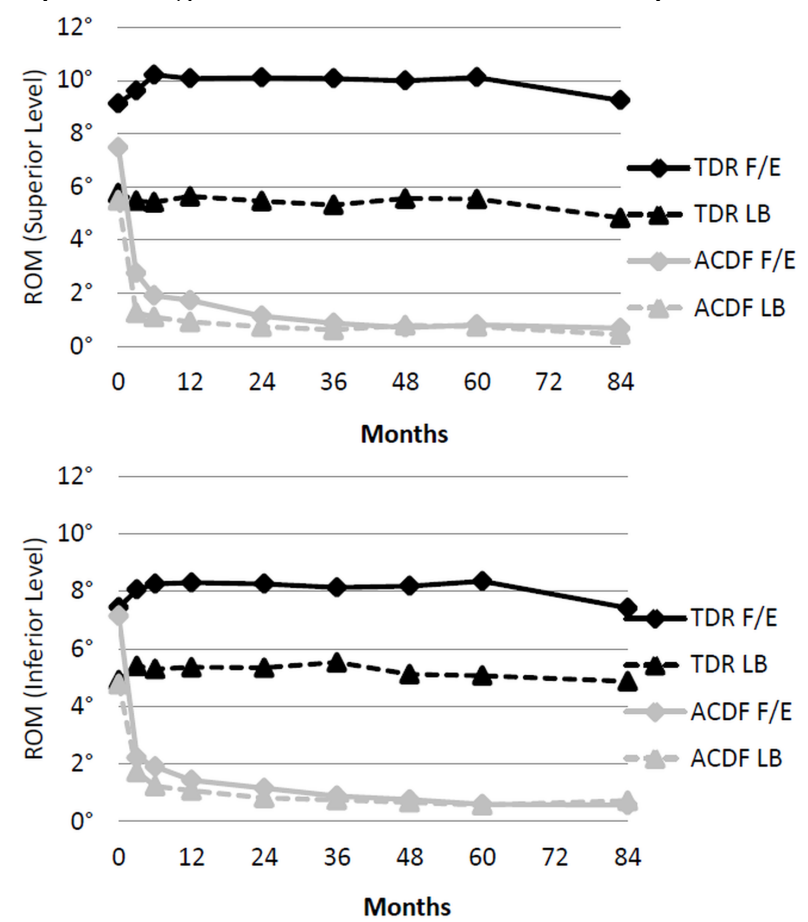

Fig. 4. Range of motion in flexion/extension (F/E) and lateral bending (LB) for two level patients. Top: Range of motion at the superior level. Bottom: Range of motion at the inferior level.

Table 4. Outcomes for 2-Level TDR and ACDF.

\begin{tabular}{|c|c|c|c|c|c|c|c|}
\hline Study & Outcome & Treatment arm & Baseline & 7 Years & Mean $\Delta$ at 7 years* & P value ${ }^{\dagger}$ & Recovery Ratio \\
\hline \multirow[t]{9}{*}{ 2-Level } & NDI & TDR & $53.8 \pm 15.4$ & $18.0 \pm 19.1$ & $35.6 \pm 20.3$ & 0.04 & $67 \%$ \\
\hline & & $\mathrm{ACDF}$ & $55.7 \pm 15.2$ & $26.2 \pm 22.4$ & $28.2 \pm 21.7$ & & $53 \%$ \\
\hline & VAS neck pain & TDR & $71.2 \pm 20.5$ & $19.0 \pm 27.1$ & $50.9 \pm 30.6$ & 0.21 & $72 \%$ \\
\hline & VAS arm pain & TDR & $68.8 \pm 25.0$ & $15.9 \pm 25.7$ & $54.1 \pm 32.8$ & 0.99 & $74 \%$ \\
\hline & & $\mathrm{ACDF}$ & $73.1 \pm 21.9$ & $18.4 \pm 27.0$ & $55.1 \pm 32.0$ & & $76 \%$ \\
\hline & SF-12 PCS & TDR & $33.4 \pm 6.7$ & $46.3 \pm 11.1$ & $12.7 \pm 10.9$ & 0.55 & $19 \%$ \\
\hline & & $\mathrm{ACDF}$ & $32.5 \pm 7.7$ & $43.7 \pm 11.9$ & $10.3 \pm 11.4$ & & $15 \%$ \\
\hline & SF-12 MCS & TDR & $41.9 \pm 11.3$ & $52.0 \pm 10.1$ & $10.5 \pm 12.7$ & 0.30 & $16 \%$ \\
\hline & & $\mathrm{ACDF}$ & $42.0 \pm 12.0$ & $49.1 \pm 12.7$ & $7.2 \pm 14.3$ & & $10 \%$ \\
\hline
\end{tabular}

* Mean of differences in outcomes between 7 years and preoperative follow-up. $†$ Adjusted p-value for difference in change from baseline between TDR and ACDF at 7-year follow-up.Values given are mean \pm SD unless otherwise indicated.NDI, neck disability index; VAS, visual analog scale; SF-12, Short Form 12-item Health Survey; MCS, Mental Composite Score; PCS, Physical Composite Score. 
did at both the treated and adjacent levels. By 7 years, subsequent surgeries at the treated level, defined as any reoperation, revision, removal, or supplemental fixation, occurred in $4.4 \%(10 / 225)$ of TDR patients and $16.2 \%(17 / 105)$ of ACDF patients $(\mathrm{p}=0.0008)$. The TDR secondary surgeries were Removal (5), Reoperation (2), Revision (2) and Supplemental Fixation (1). Among ACDF patients, the secondary surgeries were Removal (8), Revision (4), Supplemental Fixation (3) and Reoperation (2). Discounting the plate removals at the index level (presumably to be able to access adjacent level pathology), the adjusted index level secondary surgery rate for ACDF was 10.5\% for two-level. The most common reason for additional surgical intervention at the index level(s) was persistent radiculopathy and/or neck pain $(n=7)$ and pseudoarthrosis $(n=9)$, for the TDR and ACDF group, respectively. In the TDR group, there was one case of device migration that was asymptomatic, and one case of instability of the TDR due to over-preparation of the vertebral endplate that required surgical intervention. Subsequent surgeries that involved at least one adjacent level occurred in $4.4 \%(10 / 225)$ of TDR patients and $11.4 \%$ $(12 / 105)$ of ACDF patients $(\mathrm{p}=0.03)$. The most common reason for additional surgical intervention at an adjacent level was adjacent level disease or herniation for both the TDR $(\mathrm{n}=10)$ and $\operatorname{ACDF}(\mathrm{n}=8)$ group. Kaplan-Meier survival function estimates demonstrated that TDR patients were less likely to have subsequent surgery due to either index or adjacent level indications (Figure 5).

\section{One-Level Treatment Arm}

Primary Success Analysis - Single level

Based on the FDA required measure of composite success, there was no significant difference in overall success between TDR and ACDF in the single level cohort patients. Therefore, one-level TDR demonstrated non-inferiority compared to one-level ACDF at 7 years (Table 7 ; Figure 6 ). The rate of success was 55.2\% (64/116) in the TDR group and 50.0\% (25/ $50)$ in the ACDF group with a difference of $5.2 \%$ and lower $95 \%$ confidence bound of the difference of $-8.7 \%$. The main driver of the (nonsignificant) difference in success rates was a significantly lower incidence of subsequent surgery at the index level in TDR patients (TDR 3.0\% vs ACDF 12.3\%; Table 7).

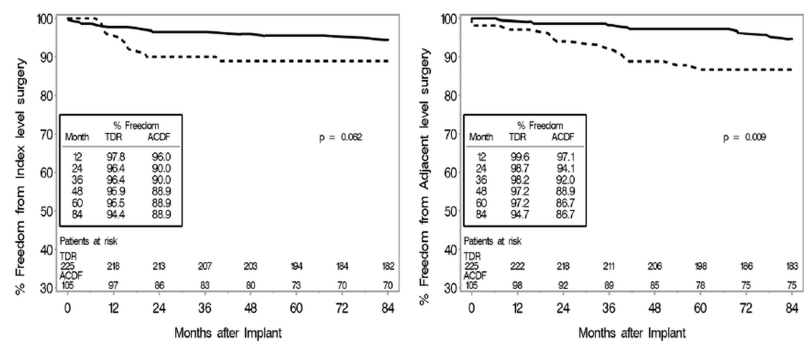

Fig. 5. Kaplan-Meier survival function estimates for subsequent surgery in two-level patients. P-value based on log-rank test. Left: Subsequent surgery for index level indications. Right: Subsequent surgery at the adjacent level.

Table 6. Radiographic Outcomes for 2-Level TDR and ACDF at 7 years.

\begin{tabular}{|c|c|c|c|}
\hline Outcome & Treatment & Superior Level & Inferior Level \\
\hline \multirow[t]{2}{*}{ ROM in Flexion/Extension } & TDR & $9.3 \pm 5.8^{\circ}$ & $7.4 \pm 5.2^{\circ}$ \\
\hline & $\mathrm{ACDF}$ & $0.2 \pm 0.2^{\circ}$ & $0.6 \pm 0.8^{\circ}$ \\
\hline \multirow[t]{2}{*}{ ROM in Lateral Bending } & TDR & $4.8 \pm 3.4^{\circ}$ & $4.9 \pm 3.4^{\circ}$ \\
\hline & $\mathrm{ACDF}$ & $0.4 \pm 0.4^{\circ}$ & $0.7 \pm 0.9^{\circ}$ \\
\hline \multirow[t]{2}{*}{ FSU Height Change from PreOp } & TDR & $0.8 \pm 1.2 \mathrm{~mm}$ & $0.2 \pm 1.1 \mathrm{~mm}$ \\
\hline & $\mathrm{ACDF}$ & $1.5 \pm 0.8 \mathrm{~mm}$ & $1.6 \pm 0.9 \mathrm{~mm}$ \\
\hline \multirow[t]{2}{*}{ FSU Height Change from PostOp* } & TDR & $-0.5 \pm 0.4 \mathrm{~mm}$ & $-0.4 \pm 0.4 \mathrm{~mm}$ \\
\hline & $\mathrm{ACDF}$ & $-0.7 \pm 0.7 \mathrm{~mm}$ & $-0.9 \pm 0.9 \mathrm{~mm}$ \\
\hline \multirow[t]{2}{*}{ Adjacent Segment Degeneration } & TDR & $37.5 \%(57 / 152)$ & $30.3 \%(33 / 109)$ \\
\hline & $\mathrm{ACDF}$ & $80.8 \%(42 / 52)$ & $66.7 \%(28 / 42)$ \\
\hline
\end{tabular}

Values given are mean \pm SD unless otherwise indicated. * Prior to discharge from hospital. 
Patient Reported Outcomes - Single level

Mean NDI scores improved significantly for both groups by six weeks, and improvement was maintained though seven years in both groups compared to baseline (Figure 7). There was no statistically significant difference between groups in global NDI in the single level cohort averaged across all time points $(\mathrm{p}=0.11)$. While the TDR group showed greater improvement at early time points, both groups demonstrated comparable mean NDI scores and mean NDI improvement from baseline (TDR $35.4 \pm 20.6 \mathrm{vs}$ $\mathrm{ACDF} 33.8 \pm 20.2 ; \mathrm{p}=0.99)$ at the specific seven year endpoint (Table 8). On average, NDI recovery ratios improved $67 \%$ over baseline in the TDR patients and $64 \%$ over baseline in the ACDF patients. For onelevel patients, the most improved NDI item was Recreation for both ACDF (2.4 points) and TDR (2.4 points). Both the mean improvement (35 points) and the recovery ratio (67\%) are strikingly similar in the one- and two-level TDR cohorts. Similarly, for VAS neck pain and arm pain scores, both groups saw a significant improvement from baseline by six weeks, which was maintained through seven years (Table 8). There was no statistically significant difference in global VAS neck pain in the single level cohort averaged across all time points. The TDR group

Table 7. Overall success and components of success for 1-level TDR and ACDF.

\begin{tabular}{|l|r|r|r|}
\hline & TDR & ACDF & Difference \\
\hline Composite success & $55.2 \%$ & $50.0 \%$ & $5.2 \% *$ \\
\hline Subsequent Surgery & $3.0 \%$ & $12.3 \%$ & $9.3 \% \dagger$ \\
\hline Radiographic failure & $9.3 \%$ & $4.5 \%$ & $4.8 \%$ \\
\hline Adverse events & $6.1 \%$ & $3.7 \%$ & $2.4 \%$ \\
\hline NDI success & $76.5 \%$ & $77.8 \%$ & $1.3 \%$ \\
\hline Neurologic failure & $11.4 \%$ & $11.5 \%$ & $0.1 \%$ \\
\hline
\end{tabular}

* Non-inferiority of TDR vs. ACDF established with $95 \%$ lower confidence bound of difference $>-10 \%$. $\dagger p<0.05$; Fisher's exact test.

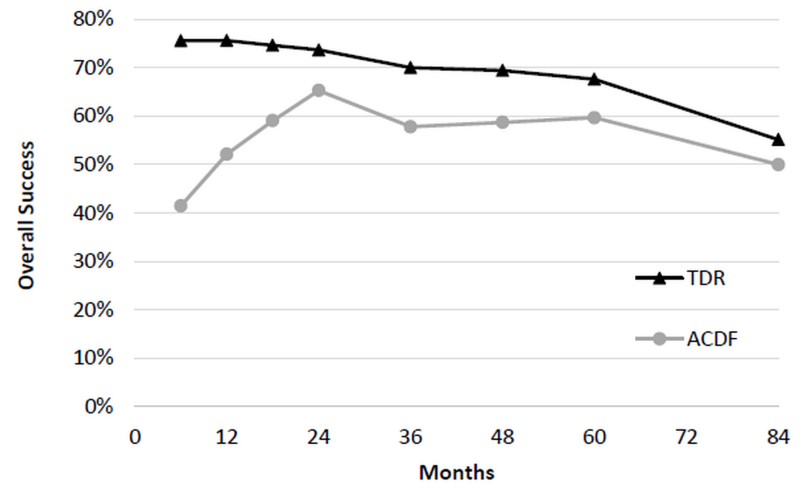

Fig. 6. Overall treatment success of one-level TDR and ACDF. showed a greater level of VAS Neck Pain improvement at early time points, but this difference attenuated at the seven year endopint, where both groups showed a similar level of pain score improvement (TDR 51.1 \pm 33 vs ACDF 48.2 \pm 30 ; Table 8). Overall, both groups of patients had similar VAS neck pain recovery ratios (71\% TDR vs $67 \%$ ACDF). Again, the single level TDR VAS neck pain improvement $(51 \pm 33)$ and recovery ratio $(71 \%)$ was strikingly similar to the two-level cohort (Table 8). There was a significantly lower global VAS arm pain in the TDR cohort averaged across all time points $(\mathrm{p}=0.03)$. However, at the specific 7 year endpoint, there was no significant difference in VAS arm pain between groups $(\mathrm{p}=0.35$, Table 8$)$.

In the single level cohort, the vast majority of patients demonstrated improvement in NDI (84.6\% TDR and $84.8 \%$ ACDF). Similarly, there was a strikingly low percentage of patients who had worse NDI scores in the single level cohort (1.2\% TDR and 2.5\% ACDF; Table 9). Overall, the vast majority of patients demonstrated improvement in VAS neck pain in the single level cohort (87.5\% TDR and 83.8\% ACDF; $p=0.21$ ). Similarly, there was a strikingly low percentage of patients who had worse NDI scores in the single level cohort (3.8\% TDR and 1.3\% ACDF;
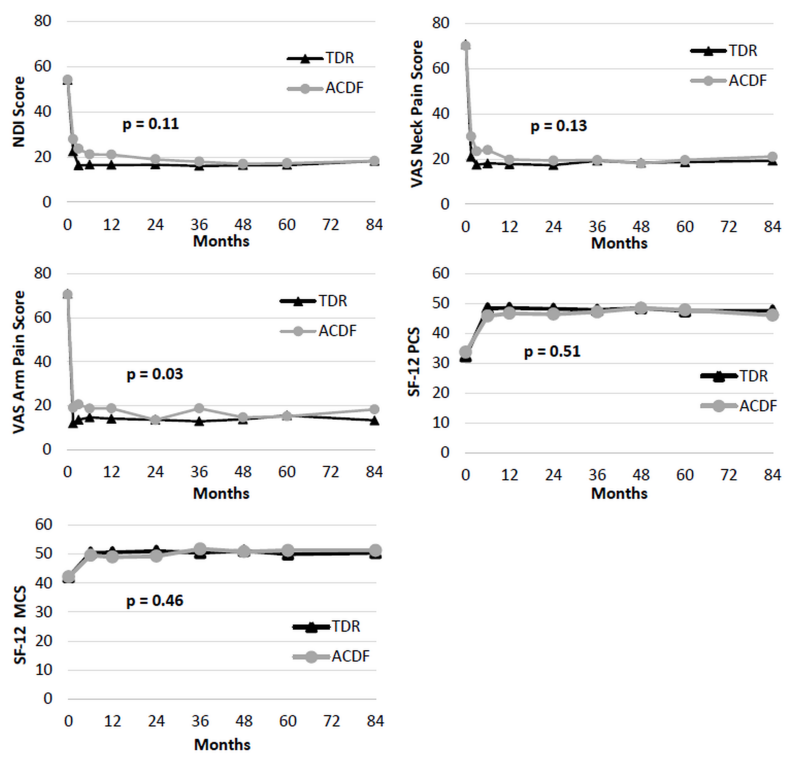

Fig. 7. Patient reported outcomes for one-level TDR and ACDF Patients from preoperative to 7 years follow-up. P-values are from a global test of the difference between TDR and ACDF patient scores, generalized across all time points. Top Left: Mean NDI scores. Top Right: Mean VAS Neck Pain Scores. Middle Left: Mean VAS Arm Pain Scores. Middle Right: Mean SF-12 PCS. Bottom Left: Mean SF-12 MCS. 
Table 9).

Overall, patients saw a significant improvement in SF-12 PCS/MCS scores, and both treatment groups had similar SF-12 scores through seven years (Figure 7; Table 8).

Both groups maintained a high level of patient satisfaction, calculated as the proportion of patients who answered "very satisfied" for the satisfaction questionnaire [TDR: $90.9 \%$ (120/132) vs. ACDF: 77.8\% $(42 / 54) ; p=0.028]$. A high proportion of patients from both groups answered that they would "definitely" or "probably" recommend their treatment to a friend [TDR: $96.2 \%(127 / 132)$ vs. ACDF: $88.9 \%$ $(48 / 54) ; \mathrm{p}=0.08]$.

Table 8. Outcomes for 1-Level TDR and ACDF.

\begin{tabular}{|c|c|c|c|c|c|c|c|}
\hline Study & Outcome & Treatment arm & Baseline & 7 Years & Mean $\Delta$ at 7 years* & P-value $\dagger$ & Recovery Ratio \\
\hline \multirow[t]{10}{*}{ 1-Level } & NDI & TDR & $54.0 \pm 14.0$ & $17.9 \pm 19.7$ & $35.4 \pm 20.6$ & 0.99 & $67 \%$ \\
\hline & & $\mathrm{ACDF}$ & $54.1 \pm 14.6$ & $18.2 \pm 17.6$ & $33.8 \pm 20.2$ & & $64 \%$ \\
\hline & VAS neck pain & TDR & $70.8 \pm 22.4$ & $19.0 \pm 26.9$ & $51.1 \pm 33.3$ & 0.89 & $71 \%$ \\
\hline & & $\mathrm{ACDF}$ & $70.1 \pm 21.5$ & $21.1 \pm 24.4$ & $48.2 \pm 30.1$ & & $67 \%$ \\
\hline & VAS arm pain & TDR & $71.0 \pm 23.8$ & $12.8 \pm 23.3$ & $57.5 \pm 33.7$ & 0.35 & $73 \%$ \\
\hline & & $\mathrm{ACDF}$ & $70.7 \pm 26.8$ & $20.9 \pm 27.1$ & $53.2 \pm 36.2$ & & $63 \%$ \\
\hline & SF-12 PCS & TDR & $32.5 \pm 5.9$ & $47.8 \pm 11.2$ & $15.2 \pm 11.5$ & 0.11 & $22 \%$ \\
\hline & & $\mathrm{ACDF}$ & $33.8 \pm 6.4$ & $46.1 \pm 10.1$ & $11.6 \pm 10.7$ & & $17 \%$ \\
\hline & SF-12 MCS & TDR & $42.1 \pm 13.1$ & $50.4 \pm 10.6$ & $8.0 \pm 13.7$ & 0.99 & $11 \%$ \\
\hline & & $\mathrm{ACDF}$ & $42.2 \pm 10.4$ & $51.3 \pm 10.6$ & $8.3 \pm 11.7$ & & $13 \%$ \\
\hline
\end{tabular}

* Mean of differences in outcomes between 7 years and preoperative follow-up. † Adjusted p-value for difference in change from baseline between TDR and ACDF at 7-year follow-up. Values given are mean \pm SD unless otherwise indicated. NDI, neck disability index; VAS, visual analog scale; SF-12, Short Form 12-item Health Survey; MCS, Mental Composite Score; PCS, Physical Composite Score.

Table 9. NDI and pain status (\% of patients) at last follow-up in 1-level TDR and ACDF.

\begin{tabular}{|c|c|c|c|c|c|c|}
\hline \multirow[b]{2}{*}{ Status* } & \multicolumn{3}{|r|}{ NDI } & \multicolumn{3}{|c|}{ VAS Neck Pain } \\
\hline & TDR & $\mathrm{ACDF}$ & P value $\dagger$ & TDR & $\mathrm{ACDF}$ & $\mathrm{P}$ valuet \\
\hline Improved & $84.6 \%$ & $84.8 \%$ & 0.72 & $87.5 \%$ & $83.3 \%$ & 0.21 \\
\hline Not improved & $14.2 \%$ & $12.7 \%$ & & $8.8 \%$ & $15.4 \%$ & \\
\hline Worse & $1.2 \%$ & $2.5 \%$ & & $3.8 \%$ & $1.3 \%$ & \\
\hline
\end{tabular}

* NDI: Improved: $\geq 15 / 100$ point increase from baseline. Not improved: $<15$ point change ( \pm ) from baseline. Worse: $\leq-15 / 100$ point decrease from baseline. Neck pain: Improved: $\geq 10 / 100$ point increase from baseline. Not improved: $<10$ point change $( \pm)$ from baseline. Worse: $\leq-10 / 100$ point decrease from baseline. † Fisher's exact test. 
degeneration (65.1\%/63.0\%) than the TDR group $(40.4 \% / 43.8 \%)$ at both the superior and inferior adjacent levels, respectively (Table 10).

\section{Safety Outcomes - Single level}

CEC classified adverse events rates were similar between treatment groups as well [TDR: 6.1\% (10/164), ACDF: 3.7\% (3/81)]. TDR patients had significantly fewer subsequent surgical interventions than ACDF patients did at both the treated and adjacent levels. By 7 years, subsequent surgeries (including all secondary surgeries such as index level instrumentation removals to access adjacent level pathology) at the



Fig. 8. Range of motion in flexion/extension (F/E) and lateral bending (LB) for one level patients.

Table 10. Radiographic outcomes for 1-Level TDR and ACDF at 7 years.

\begin{tabular}{|l|r|r|}
\hline Outcome & Treatment & 7 Years \\
\hline ROM in Flexion/Extension & TDR & $10.2 \pm 6.3^{\circ}$ \\
\hline & ACDF & $0.2 \pm 0.2^{\circ}$ \\
\hline ROM in Lateral Bending & TDR & $5.1 \pm 3.5^{\circ}$ \\
\hline FSU Height Change from PreOp & ACDF & $0.4 \pm 0.4^{\circ}$ \\
\hline & TDR & $1.5 \pm 0.8 \mathrm{~mm}$ \\
\hline FSU Height Change from PostOp* & ACDF & $0.2 \pm 1.3 \mathrm{~mm}$ \\
\hline discharge from hospital. & TDR & $-0.5 \pm 0.5 \mathrm{~mm}$ \\
\hline Adjacent Segment Degeneration & ACDF & $-0.7 \pm 0.7 \mathrm{~mm}$ \\
\hline Superior Level & & \\
\hline & TCDF & $63.0^{\circ}(17 / 27)$ \\
\hline
\end{tabular}

treated level occurred in 3.0\% (5/164) of TDR patients and $12.3 \%(10 / 81)$ of ACDF patients $(\mathrm{p}=$ $0.008)$. The TDR secondary surgeries were Removal (4) and Reoperation (1). The ACDF secondary surgeries were for Removal (7) or Supplemental Fixation (3). Discounting the plate removals at the index level (presumably to access adjacent level pathology), the adjusted index level secondary surgery rate for ACDF was $6.2 \%$ for one-level. The most common reason for additional surgical intervention at the index level was persistent radiculopathy and/or neck pain $(n=3)$ and pseudoarthrosis $(n=5)$, for the TDR and ACDF group, respectively. There were no cases of device malfunction, though there was one instance where the TDR device was malpositioned and required additional surgical intervention. Additionally, there was one case in which gross motion of the caudal endplate of the TDR device was noted between flexion and extension radiographs at 3 months. It was concluded that the TDR device loosened from the vertebral endplate. Thus due to over distraction of the spinal segment, possibly caused by an oversized implant; the patient had the device removed and replaced with fusion. The surgeon-investigator opined that the loosening might have occurred due to oversizing and/or over distraction of the implant. Subsequent surgeries that involved at least one adjacent level occurred in $3.7 \%(6 / 164)$ of TDR patients and $13.6 \%(11 / 81)$ of ACDF patients $(\mathrm{p}=0.007)$. The most common reason for additional surgical intervention at an adjacent level was adjacent level disease or herniation for both the TDR $(n=4)$ and ACDF (n $=8$ ) group. Kaplan-Meier survival function estimates demonstrated that TDR patients were less likely to have subsequent surgery across time (Figure 9).

\section{Discussion}

These results indicate that cervical spine surgery for properly selected patients with myelopathy or radiculopathy is tremendously effective at improving patient pain and quality of life. Overall, greater than $95 \%$ of patients (from both groups) who underwent TDR and $88 \%$ of patients who underwent ACDF were "very satisfied" at seven years. When comparing TDR to ACDF, these results add to the growing body of literature supporting the long-term outcome and decreased secondary surgery rate of TDR com- 
pared to $\mathrm{ACDF}$.

Although the change in disease specific outcome measures and statistical testing is of value to the scientific community, patients may struggle to understand the specific implications of this data. As one recent study reported, "interpretation of the data is very difficult or even impossible for most patients due to lack of adequate knowledge." "From a patients perspective a total NDI score or a difference in NDI score, that is however important for scientific evaluation, is meaningless. It will not help him/her in decision-making about any treatment for neckrelated problems." 32 Therefore, in this study, we have attempted to transform the outcome scores into expressions that can easily be understood by patients to help them in making a decision about their eventual treatment. Here we report that the vast majority of patients in both single and two level cohorts improved in neck disability after surgery $(70.2 \%-80.8 \%$ of two-level surgeries and $84.6 \%-84.8 \%$ of single level surgeries) and neck pain (83.3\%-87.5\% of single level surgeries and $77.7 \%-86.0 \%$ of two-level surgeries).

In contrast to the conventional wisdom of " 50 percent improved and 50 percent worse" outcome distribution, the percentage of patients with worse neck disability (2.5\%-3.8\% of two-level surgeries and $1.2 \%-2.5 \%$ of single level surgeries) and worse VAS neck pain (5\%-6.8\% of two-level and $1.3 \%-3.8 \%$ of single level) was strikingly low. To further facilitate patient education and individualized treatment ap- proaches, the data in this study are also reported in terms of recovery ratios. A higher recovery ratio implies more improvement in outcome normalized to maximal possible improvement. For instance, a patient with a preoperative NDI of 80 and a postoperative NDI of 20 would have a $75 \%$ recovery ratio. In this study, patients who underwent two-level total disc replacement experienced a mean $72 \%$ reduction in neck pain, $74 \%$ improvement in arm pain, and $67 \%$ improvement in disability relative to an idealized improvement. Similarly, patients in this study who underwent a single-level total disc replacement experienced a mean $71 \%$ reduction in neck pain, $73 \%$ improvement in arm pain, and $67 \%$ improvement in disability relative to maximal possible improvement. We believe that it is imperative that our clinical trial results be translated into lay language to aid patients, non-spine providers such as insurance medical directors, and policy makers in their decision-making.

There was a clear reduction in secondary surgery rates following TDR at long-term follow-up in both the single and two level cohorts. Index level secondary surgery rates were significantly lower in the TDR population at seven years in the single level (3.0\% TDR vs $12.3 \%$ ACDF) and two level (4.4\% TDR vs $16.2 \%$ ACDF) when all index level procedures (including plate removal) were included. Radiographic pseudoarthrosis was present in $9.1 \%$ of the 2-level ACDF patients and $4.5 \%$ of the single level ACDF patients who did not undergo secondary surgery by seven years. The rate of secondary surg-


Fig. 9. Kaplan-Meier survival function estimates for subsequent surgery in one-level patients. P-value based on log-rank test. Left: Subsequent surgery for index level indications. Right: Subsequent surgery at the adjacent level. 
eries due to pseudoarthrosis was $8.6 \%$ for 2-level and $6.2 \%$ for one-level. Adjacent segment secondary surgery rates were also significantly lower in the TDR patients in the single level (3.7\% TDR vs $13.6 \%$ ACDF) and two level (4.4\% TDR vs 11.4\% ACDF) patients. The difference in adjacent level secondary surgery rates is consistent with the observed increase in radiographic adjacent segment disease rates in the ACDF patients.

Our data are consistent with other Level I evidence clinical trials that have reported on the safety and efficacy of TDR with follow-up periods up to 7 years. ${ }^{33}$ Overall, the results have been favorable for TDR, with results comparable to or better than ACDF control groups. In a 7-year study on the ProDisc-C device, Janssen et al. reported comparable results of one-level TDR compared to ACDF with respect to disease specific outcomes..$^{9}$ Additionally, investigators observed a lower rate of subsequent surgical procedures at both the treated level and adjacent levels. ${ }^{9}$ Burkus et al. published similar 7-year findings on the Prestige device with comparable or better outcomes for the TDR group with almost three times fewer index and adjacent level surgeries in the disc group. ${ }^{18}$ In a 5-year study on the PCM device, Phillips et al. reported better outcomes for neck pain, similar AE rates, and lower rates of subsequent surgery and radiographic degeneration for their one-level disc group compared to ACDF controls. ${ }^{11}$ Although some early studies of other discs did not report a statistically significant difference in secondary surgery rates at early time points, long-term follow-up has demonstrated that motion preservation reduces secondary surgery rates.

While several high-quality studies have validated the long-term safety and efficacy of one-level TDR, to the authors' knowledge, this study is one of two high-quality, randomized clinical trial to evaluate the long-term performance of two-level TDR. The results of other, short-term studies, while limited in quantity, are in accordance with these results presented here. In a prospective, randomized, 65-patient study of two-level TDR versus ACDF, Chen et al. demonstrated favorable outcomes for two-level TDR (Bryan), with significantly more improvement in NDI and neck pains scores over an ACDF compari- son group at two years. ${ }^{34}$

The dramatic difference seen between TDR and fusion when moving from one-level to two-levels of treatment is also noteworthy. ${ }^{35}$ As discussed in the results, the outcome of TDR is remarkably similar at one and two levels. Although there previously was a statistically significant difference between single level TDR and ACDF, at long term follow-up the differences in success rate, NDI score, VAS score, and other clinical outcome measures are no longer statistically significant. While one-level treatment with TDR offered similar results in patient reported outcomes versus ACDF in the long-term, a sizeable difference in treatment effectiveness was observed between two-level TDR and ACDF. Treatment with ACDF appeared to experience diminishing returns as the number of treated levels increases, while TDR does not, or does to a much lesser extent. ${ }^{35,36}$ A likely explanation for this phenomenon lies in the apparent biomechanical differences between fusion and disc replacement. ${ }^{7,37,38}$ In accordance with this hypothesis of transfer of biomechanical stresses in multilevel disc replacement, there was a striking difference in the recovery ratios of VAS neck pain between groups. In the single level cohort, neck pain improved on average $67 \%$ relative to idealized improvement from baseline score. In the two level group, neck pain improved only $57 \%$. Therefore, although the difference in mean VAS improvement is small (4 points on a $0-100$ scale), there was a $10 \%$ difference in the recovery ratio. Additionally, there was an increase in the incidence of radiographic adjacent segment degeneration in the ACDF patients between cohorts (2-level $80.8 \%$ vs $65.1 \% 1$-level). The observed increase in radiographic degeneration is also in accordance with the theory that there is increased mechanical stress following two level fusion.

There is no doubt that ACDF is still a highly useful and successful procedure, especially for treating symptomatic spondylosis accompanied by marked cervical instability, facet arthropathy, disc space collapse, or kyphosis. One limitation of this study was the specific inclusion and exclusion criteria for entry into the study. At the time of conception, the intention of the Mobi-C study was to enroll patients without significant conditions that could confound the 
outcome of an artificial disc. Other studies have demonstrated that less than half of the patients who present to a spine surgeon's office with cervical spine complaints are candidates for a TDR based upon IDE study criteria. ${ }^{39}$ Therefore, the generalizability of these results to patients outside of IDE study conditions may be limited. There may also be other variables that affect the outcome of TDR that were not captured in this report. As the understanding of TDR has improved since the conception and initiation of this study almost 10 years ago, several technical factors have been identified that may be potential confounders. For example, a retrospective analysis of the Discover disc revealed that a preoperative disk height of $<3.5 \mathrm{~mm}$ or excessive intraoperative lordosis, (such as increasing the functional spinal unit angle by $>3$ degrees) was associated with a 3.5 times greater risk of not achieving the MCID in NDI $(\mathrm{p}=0.016) .{ }^{40}$ Another recent study demonstrated that subtle micromotion between the implant and the vertebral endplates (less than the threshold for macromotion and migration described as an adverse event above) might affect clinical outcome. ${ }^{41}$ Therefore, there may also be subtle surgical factors, such as height, ${ }^{42}$ alignment, ${ }^{43,44}$ or removal of the PLL, ${ }^{44,45}$ that may affect TDR kinematics and that limit the generalizability of the results. ${ }^{44}$ Additionally, we acknowledge that the indications and rate of secondary surgery are somewhat subjective. One group of authors reported a higher rate of secondary surgery in ACDF patient within an IDE study than a concurrent group of ACDF patients outside of IDE study conditions. ${ }^{46}$ The authors inferred that IDE study conditions might lead to a subtle bias towards increased rates of secondary surgery in ACDF patients who would otherwise be managed without surgery. Although we acknowledge possible bias in the subjective decision on the part of the surgeon and patient to consider a secondary surgery, we also report concordant clinical failure measured in objective parameters such as radiographic adjacent segment disease rates and clinical outcome measures. We believe it is entirely reasonable that, in a group of patients with an increased rate of radiographic degeneration and worse clinical outcomes, we would observe an increased rate of secondary surgery. Additionally, at least $47 \%$ of secondary surgeries were performed by non-investigator surgeons, which may also reduce likelihood of investigator bias. The FDA composite success endpoint (that consists of clinical and radiographic measures) is an attempt to capture all treatment failures, including secondary surgeries or patients who have a poor outcome who choose not to undergo secondary surgery. All IDE clinical trials of TDR have used a composite success endpoint to test for non-inferiority against ACDF; however, the definition of overall success has varied among these studies. ${ }^{47}$ The composite success endpoint used the Mobi-C trial was mandated by the FDA from the beginning of the IDE and has been reported in earlier studies. ${ }^{23}$ At various times during this study, however, the FDA imposed alternative definitions of overall success. ${ }^{24,25}$ For the purposes of this study, we used the original FDA definition of success criteria. However, we acknowledge that, due to the small changes in FDA definitions of success, direct comparisons of overall success rates across studies may not be valid. Another limitation is that the study was funded by industry. Some authors perceive industry funding to induce a source of bias, although this is true for all medical device studies. Most spine device trials, particularly multicenter studies, are industry funded. ${ }^{48}$ Additionally, authors have declared potential conflicts of interest. Another source of bias was affirmation bias or confirmation bias, although that is probably true for most medical device studies. Due to the differences in postoperative rehabilitation, it was not possible to blind patients to their treatment allocation. For treating symptomatic spondylosis in which the spine is generally stable, these data suggest that the stability provided by fusion is not worth the sacrifice in motion. With an apparent reduced risk for reoperation and adjacent segment pathologies, motionpreserving treatment with TDR seems to be an excellent alternative to ACDF, given the data presented here and in many other studies.

\section{Conclusion}

For the treatment of one- or two-level symptomatic cervical disc disease, TDR with the Mobi-C Cervical Disc is a safe procedure with excellent long-term effectiveness. Compared to an anterior fusion alterative, TDR provided a similar reduction in patient reported outcomes of pain and function while providing a lower risk for reoperation at both treated and 
adjacent levels. The improvement in outcome between TDR and ACDF appears to be durable from the two-year to the seven-year follow up. The difference in clinical effectiveness of TDR versus ACDF becomes more apparent as treatment increases from one to two levels, indicating a significant benefit for TDR over ACDF for two-level procedures.

\section{Acknowledgements}

Current affiliation of Dr. Davis is the Tampa Laser Spine Institute, Tampa, Florida. The authors would like to thank the other principal investigators for their contributions to the study: Guy Danielson III, MD; Charlie Gordon, MD; Daniel Peterson, MD; John Stokes, MD; Arnold Schwartz, MD; Ali Araghi, MD; David Tahernia MD; Hazem Eltahawy MD; Reginald Tall, MD; Douglas Wong, MD; Gerald Schell, MD; Michael Ramsey, MD; B. Christoph Meyer, MD; Robert McLain, MD; Jon Park, MD; Ed Simmons, MD; Mark Stern, MD; Phillip S. Yuan, MD. The authors would also like to thank Kyle Marshall and Elizabeth Roberts for their assistance with the preparation of the manuscript.

\section{References}

1. Daffner SD, Hilibrand AS, Hanscom BS, Brislin BT, Vaccaro AR, Albert TJ. Impact of neck and arm pain on overall health status. Spine (Phila $\mathrm{Pa}$ 1976). 2003 Sep 1;28(17):2030-5.

2. Murray CJ, Barber RM, Foreman KJ, Abbasoglu Ozgoren A, Abd-Allah F, Abera SF, et al. Global, regional, and national disability-adjusted life years (DALYs) for 306 diseases and injuries and healthy life expectancy (HALE) for 188 countries, 1990-2013: quantifying the epidemiological transition. Lancet. 2015 Nov 28;386(10009):2145-91. 3. Hilibrand AS, Carlson GD, Palumbo MA, Jones PK, Bohlman HH. Radiculopathy and myelopathy at segments adjacent to the site of a previous anterior cervical arthrodesis. J Bone Joint Surg Am. 1999 Apr;81(4):519-28.

4. Fuller DA, Kirkpatrick JS, Emery SE, Wilber RG, Davy DT. A kinematic study of the cervical spine before and after segmental arthrodesis. Spine (Phila Pa 1976). 1998 Aug 1;23(15):1649-56.
5. Park DK, Lin EL, Phillips FM. Index and adjacent level kinematics after cervical disc replacement and anterior fusion: in vivo quantitative radiographic analysis. Spine (Phila Pa 1976). $2011 \mathrm{Apr}$ 20;36(9):721-30.

6. Matsunaga S, Kabayama S, Yamamoto T, Yone K, Sakou T, Nakanishi K. Strain on Intervertebral Discs After Anterior Cervical Decompression and Fusion. Spine. 1999;24(7):670-5.

7. Elsawaf A, Mastronardi L, Roperto R, Bozzao A, Caroli M, Ferrante L. Effect of cervical dynamics on adjacent segment degeneration after anterior cervical fusion with cages. Neurosurgical Review.

2008;32(2):215-24.

8. Murrey D, Janssen M, Delamarter R, Goldstein J, Zigler J, Tay B, et al. Results of the prospective, randomized, controlled multicenter Food and Drug Administration investigational device exemption study of the ProDisc-C total disc replacement versus anterior discectomy and fusion for the treatment of 1-level symptomatic cervical disc disease. The Spine Journal. 2009 Apr;9(4):275-86.

9. Janssen ME, Zigler JE, Spivak JM, Delamarter RB, Darden BV, 2nd, Kopjar B. ProDisc-C Total Disc Replacement Versus Anterior Cervical Discectomy and Fusion for Single-Level Symptomatic Cervical Disc Disease: Seven-Year Follow-up of the Prospective Randomized U.S. Food and Drug Administration Investigational Device Exemption Study. J Bone Joint Surg Am. 2015 Nov 4;97(21):1738-47.

10. Mummaneni PV, Burkus JK, Haid RW, Traynelis VC, Zdeblick TA. Clinical and radiographic analysis of cervical disc arthoplasty compared with allograft fusion: a randomized controlled clinical trial. Journal of Neurosurgery: Spine.

2007;6(3):198-209.

11. Phillips FM, Geisler FH, Gilder KM, Reah C, Howell KM, McAfee PC. Long-term Outcomes of the US FDA IDE Prospective, Randomized Controlled Clinical Trial Comparing PCM Cervical Disc Arthroplasty With Anterior Cervical Discectomy and Fusion. Spine (Phila Pa 1976). 2015 May 15;40(10):674-83.

12. Phillips FM, Lee JY, Geisler FH, Cappuccino A, Chaput CD, DeVine JG, et al. A prospective, randomized, controlled clinical investigation comparing 
PCM cervical disc arthroplasty with anterior cervical discectomy and fusion. Spine. 2013;38(15):E907-18. 13. Davis RJ, Kim KD, Hisey MS, Hoffman GA, Bae HW, Gaede SE, et al. Cervical total disc replacement with the Mobi-C cervical artificial disc compared with anterior discectomy and fusion for treatment of 2-level symptomatic degenerative disc disease: a prospective, randomized, controlled multicenter clinical trial. Journal of Neurosurgery Spine. 2013 Nov;19(5):532-45.

14. Hisey MS, Bae HW, Davis R, Gaede S, Hoffman G, Kim K, et al. Prospective, Randomized Comparison of Cervical Total Disc Replacement vs. Anterior Cervical Fusion: Results at 48 Months Followup. Journal of Spinal Disorders \& Techniques. 2015;28(4):237-43.

15. Jackson RJ, Davis RJ, Hoffman GA, Bae HW, Hisey MS, Kim KD, et al. Subsequent surgery rates after cervical total disc replacement using a Mobi-C Cervical Disc Prosthesis versus anterior cervical discectomy and fusion: a prospective randomized clinical trial with 5-year follow-up. J Neurosurg Spine. 2016 May;24(5):734-45.

16. Delamarter RB, Zigler J. Five-Year Reoperation Rates, Cervical Total Disc Replacement Versus Fusion, Results of a Prospective Randomized Clinical Trial. Spine. 2013;38(9):711-7.

17. Luo J, Gong M, Huang S, Yu T, Zou X. Incidence of adjacent segment degeneration in cervical disc arthroplasty versus anterior cervical decompression and fusion meta-analysis of prospective studies. Arch Orthop Trauma Surg. 2015 Feb;135(2):155-60. 18. Burkus JK, Traynelis VC, Haid RW, Jr., Mummaneni PV. Clinical and radiographic analysis of an artificial cervical disc: 7-year follow-up from the Prestige prospective randomized controlled clinical trial. Journal of Neurosurgery: Spine. 2014 Jul 18:1-13.

19. Radcliff K, Zigler J, Zigler J. Costs of Cervical Disc Replacement Versus Anterior Cervical Discectomy and Fusion for Treatment of Single-Level Cervical Disc Disease. Spine. 2015;40(8):521-9.

20. Ament JD, Yang Z, Nunley P, Stone MB, Kim KD. Cost-effectiveness of Cervical Total Disc Replacement vs Fusion for the Treatment of 2-Level Symptomatic Degenerative Disc Disease. JAMA Surg. 2014 Dec 1;149(12):1231-9.
21. Gandhi AA, Kode S, DeVries NA, Grosland NM, Smucker JD, Fredericks DC. Biomechanical Analysis of Cervical Disc Replacement and Fusion Using Single Level, Two Level, and Hybrid Constructs. Spine (Phila Pa 1976). 2015 Oct

15;40(20):1578-85.

22. Hisey MS, Bae H, Davis R, Gaede S, Hoffman G, Kim K, et al. Multi-center, Prospective, Randomized, Controlled Investigational Device Exemption Clinical Trial Comparing Mobi C Cervical Artificial Disc to Anterior Discectomy and Fusion in the Treatment of Symptomatic Degenerative Disc Disease in the Cervical Spine. International Journal of Spine Surgery. 2014;8.

23. Davis RJ, Nunley PD, Kim KD, Hisey MS, Jackson RJ, Bae HW, et al. Two-level total disc replacement with Mobi-C cervical artificial disc versus anterior discectomy and fusion: a prospective, randomized, controlled multicenter clinical trial with 4-year follow-up results. J Neurosurg Spine. 2015 Jan;22(1):15-25.

24. Radcliff K, Coric D, Albert T. Five-year clinical results of cervical total disc replacement compared with anterior discectomy and fusion for treatment of 2-level symptomatic degenerative disc disease: a prospective, randomized, controlled, multicenter investigational device exemption clinical trial. J Neurosurg Spine. 2016 Mar 25:1-12.

25. Hisey MS, Zigler JE, Jackson R, Nunley PD, Bae HW, Kim KD, et al. Prospective, Randomized Comparison of One-level Mobi-C Cervical Total Disc Replacement vs. Anterior Cervical Discectomy and Fusion: Results at 5-year Follow-up. Int J Spine Surg. 2016;10:10.

26. Hirabayashi K, Miyakawa J, Satomi K, Maruyama T, Wakano K. Operative results and postoperative progression of ossification among patients with ossification of cervical posterior longitudinal ligament. Spine (Phila Pa 1976). 1981 JulAug;6(4):354-64.

27. McAfee PC, Cunningham BW, Devine J, Williams E, Yu-Yahiro J. Classification of Heterotopic Ossification (HO) in Artificial Disk Replacement. Journal of Spinal Disorders \& Techniques. 2003;16(4):384-9.

28. Mehren C, Suchomel P, Grochulla F, Barsa P, Sourkova P, Hradil J, et al. Heterotopic ossification in 
total cervical artificial disc replacement. Spine (Phila Pa 1976). 2006 Nov 15;31(24):2802-6.

29. Kellgren JH, Lawrence JS. Radiological assessment of osteo-arthrosis. Ann Rheum Dis. 1957 Dec;16(4):494-502.

30. Weaver EN, Jr. Letter to the Editor: Mobi-C cervical artificial disc. J Neurosurg Spine. 2016 Mar;24(3):515.

31. Guidance for Industry and FDA Staff: Clinical Data Presentations for Orthopedic Device Applications. Silver Spring, MD U.S. Food and Drug Administration; 2015 [updated 6/23/2015; cited 2016 5/19/2016].

32. Donk R, Verbeek A, Verhagen W, Groenewoud H, Hosman A, Bartels R. The Qualification of Outcome after Cervical Spine Surgery by Patients Compared to the Neck Disability Index. PLoS One. 2016;11(8):e0161593.

33. Gornet MF, Lanman TH, Burkus JK, Dryer RF, McConnell JR, Hodges SD. Two-level cervical disc arthroplasty with Prestige LP disc versus anterior cervical discectomy and fusion: seven-year outcomes of a prospective, randomized IDE clinical trial. The Spine Journal 2016;16(10):2198-9. (Abstract Only). 34. Cheng L, Nie L, Zhang L, Hou Y. Fusion versus Bryan Cervical Disc in two-level cervical disc disease: a prospective, randomised study. International orthopaedics. 2009 Oct;33(5):1347-51.

35. Bae HW, Kim KD, Nunley PD, Jackson RJ, Hisey MS, Davis RJ, et al. Comparison of Clinical Outcomes of 1- and 2-Level Total Disc Replacement: Four-Year Results From a Prospective, Randomized, Controlled, Multicenter IDE Clinical Trial. Spine (Phila Pa 1976). 2015 Jun 1;40(11):759-66.

36. Zigler JE, Rogers RW, Ohnmeiss DD. Comparison of 1-Level Versus 2-Level Anterior Cervical Discectomy and Fusion: Clinical and Radiographic Follow-Up at 60 Months. Spine (Phila Pa 1976). 2016 Mar;41(6):463-9.

37. Cunningham BW, Hu N, Zorn CM, McAfee PC. Biomechanical comparison of single- and twolevel cervical arthroplasty versus arthrodesis: effect on adjacent-level spinal kinematics. The Spine Journal. 2010 Apr;10(4):341-9.

38. Wigfield C, Gill S, Nelson R, Langdon I, Metcalf $\mathrm{N}$, Robertson J. Influence of an artificial cervical joint compared with fusion on adjacent-level motion in the treatment of degenerative cervical disc disease. Journal of Neurosurgery: Spine.

2002;96(1):17-21.

39. Auerbach JD, Jones KJ, Fras CI, Balderston JR, Rushton SA, Chin KR. The prevalence of indications and contraindications to cervical total disc replacement. Spine J. 2008 Sep-Oct;8(5):711-6.

40. Rihn JA, Radcliff K, Hipp J, Vaccaro AR, Hilibrand AS, Anderson DG, et al. Radiographic variables that may predict clinical outcomes in cervical disk replacement surgery. J Spinal Disord Tech. 2015 Apr;28(3):106-13.

41. Skeppholm M, Svedmark P, Noz ME, Maguire GQ, Jr., Olivecrona H, Olerud C. Evaluation of mobility and stability in the Discover artificial disc: an in vivo motion study using high-accuracy 3D CT data. J Neurosurg Spine. 2015 Jun 5:1-7.

42. Peng CW, Quirno M, Bendo JA, Spivak JM, Goldstein JA. Effect of intervertebral disc height on postoperative motion and clinical outcomes after Prodisc-C cervical disc replacement. Spine J. 2009 Jul;9(7):551-5.

43. Kim SW, Paik SH, Oh JK, Kwak YH, Lee HW, You KH. The impact of coronal alignment of device on radiographic degeneration in the case of total disc replacement. Spine J. 2016 Apr;16(4):470-9.

44. Yu CC, Hao DJ, Ma YL, Huang DG, Li HK, Feng H, et al. The Role of Posterior Longitudinal Ligament in Cervical Disc Replacement: An Ovine Cadaveric Biomechanical Analysis. Med Sci Monit. 2016;22:1843-9.

45. McAfee PC, Cunningham B, Dmitriev A, Hu N, Woo Kim S, Cappuccino A, et al. Cervical disc replacement-porous coated motion prosthesis: a comparative biomechanical analysis showing the key role of the posterior longitudinal ligament. Spine (Phila Pa 1976). 2003 Oct 15;28(20):S176-85.

46. Singh K, Phillips FM, Park DK, Pelton MA, An HS, Goldberg EJ. Factors affecting reoperations after anterior cervical discectomy and fusion within and outside of a Federal Drug Administration investigational device exemption cervical disc replacement trial. The Spine Journal. 2012 May;12(5):372-8. 47. Gornet MF, Burkus JK, Shaffrey ME, Argires PJ, Nian H, Harrell FE, Jr. Cervical disc arthroplasty with PRESTIGE LP disc versus anterior cervical discectomy and fusion: a prospective, multicenter inves- 
tigational device exemption study. J Neurosurg Spine. 2015 Jul 31:1-16.

48. Cher DJ, Capobianco RA. Spine device clinical trials: design and sponsorship. Spine J. 2015 May 1;15(5):1133-40.

\section{Disclosures \& COI}

The device manufacturer, Zimmer Biomet (formerly LDR Spine), sponsored the Mobi-C ${ }^{\odot}$ Cervical Disc FDA IDE clinical trial. Zimmer Biomet contributed to the design and conduct of the study and provided assistance with analysis of data and manuscript review. The authors also report receiving writing or editorial assistance for this paper from Zimmer Biomet. Dr. Radcliff: unpaid consultant for 4 Web Medical; board or committee member for ACSR; paid consultant for Altus Spine; paid consultant, research support, and unpaid consultant for DePuy, a Johnson \& Johnson Company; intellectual property (IP) royalties, paid consultant, and research support from Globus Medical; unpaid consultant for Zimmer Biomet; paid consultant and research support from Medtronic; other financial or material support from NEXXT Spine; other financial or material support from NuVasive; paid consultant for Orthofix, Inc.; IP royalties and paid consultant for Orthopedic Sciences, Inc.; research support from Pacira pharmaceuticals; research support from Paradigm Spine; and other financial or material support from Stryker. Dr. Davis: consultant for Zimmer Biomet and Titan Spine. Dr. Bae: patent holder for Zimmer Biomet; research support from Zimmer Biomet; paid consultant for Zimmer Biomet; receives royalties for products from NuVasive, Stryker, and Zimmer Biomet. Dr. Hisey: consultant for Zimmer Biomet, DePuy/ Synthes Spine, and SAB Innovasis; patent holder for Zimmer Biomet. Dr. Nunley: direct stock ownership in Amedica, Paradigm Spine, and Spineology; has received support of non-study-related clinical or research effort from the Cervical Spine Research Society, K2M, Axiomed, Medtronic, Nutech, NuVasive, Spinal Motion, and Vertiflex; is a patent holder for K2M and Zimmer Biomet (specifically for the ROI-A anterior lumbar interbody fusion cage); is a consultant for Nutech, Amedica, K2M, and Zimmer Biomet; and has received royalties, performed speaking and teaching arrangements, and served on the scientific advisory board of Osprey Biomedical and K2M. Dr. Hoffman: direct stock ownership in Zimmer Biomet and Nanovis. Dr. Jackson: consultant for Zimmer Biomet; has received clinical or research support for this study from Zimmer Biomet; receives royalties from Globus Medical; stock ownership in Medtronic and Johnson and Johnson. Dr. Albert: board or committee member for Scoliosis Reseach Society; stock or stock options from ASIP; IP royalties from Biomet; stock or stock options from Biometrix; stock or stock options from Breakaway Imaging; stock or stock options from Crosstree; IP royalties and paid consultant for DePuy, a Johnson \& Johnson Company; stock or stock options from Gentis; stock or stock options from InViVo Therapeutics; stock or stock options from Invuity; publishing royalties, financial or material support from Jay Pee; editorial or governing board Journal of Bone and Joint Surgery(American); stock or stock options in Paradigm Spine; publishing royalties, financial or material support from Saunders/Mosby-Elsevier; editorial or governing board forSpine; editorial or governing board for Spine Deformity Journal; stock or stock options in Spinicity; publishing royalties, financial or material support from Thieme; other financial or material support from United Healthcare; and stock or stock options in Vertech. Dr. Coric: royalties, stock ownership, and consultant for Spine Wave; stock ownership in DiscGenics and Spinal Kinetics; and consultant for Medtronic, Globus Medical, Stryker, and United Healthcare; and speaking and/or teaching arrangements for Globus.

\section{Corresponding Author}

Dr. Kris Radcliff, Rothman Institute, 2500 English Creek Avenue Building, 1300 Egg Harbor Township, NJ 08234. kris.radcliff@rothmaninstitute.com.

Published 28 November 2017.

This manuscript is generously published free of charge by ISASS, the International Society for the Advancement of Spine Surgery. Copyright ๑ 2017 ISASS. To see more or order reprints or permissions, see http://ijssurgery.com. 